\title{
Profibrotic Activity of Multiwalled Carbon Nanotubes Upon Prolonged Exposures in Different Human Lung Cell Types
}

\author{
Savvina Chortarea, ${ }^{1,2}$ Fikad Zerimariam, ${ }^{1}$ Hana Barosova, ${ }^{1}$ Dedy Septiadi, \\ Martin J.D. Clift, ${ }^{1,3}$ Alke Petri-Fink, ${ }^{1,4}$ and Barbara Rothen-Rutishauser ${ }^{1}$
}

\begin{abstract}
Introduction: The expanding use of multiwalled carbon nanotubes (MWCNTs) in various consumer and industrial products has raised concerns regarding the potential health risks following the inhalation of this nanomaterial. Recent studies indicate that MWCNT exposure can cause deleterious lung effects. Pulmonary fibrosis is one of the diseases associated with the inhalation of classical fiber-shaped materials (e.g., asbestos), and recently MWCNTs.

Materials and Methods: Herein, the presented work investigated early signs of fibrosis in key human lung cell types implicated directly (fibroblasts) or indirectly (alveolar epithelial cells and macrophages) in the pathogenesis of lung fibrosis, upon acute ( 24 hours) and prolonged (96 hours) exposure to different concentrations (5-20 $\mu \mathrm{g} / \mathrm{mL})$ of long, rigid Mitsui-7 MWCNTs. These results were compared to those inflicted upon the same cell types following exposure to tangled nanofibers, that is, Nanocyl-7000, and a positive particle control, crystalline quartz (i.e., Min-U-Sil).

Results: Mitsui-7 interacted with all cell types tested, in particular, single nanotubes were readily internalized by each cell type. Exposure to Mitsui-7 resulted in a proinflammatory response in macrophages at 24 hours (interleukin-1 $\beta$ release). However, only prolonged Mitsui-7 exposure induced a significant release of profibrotic mediators (transforming growth factor- $\beta$, platelet derived-growth factor, and osteopontin) in all tested cell cultures and concentrations, highlighting the importance of prolonged exposure studies in nanosafety assessment. This elevated release of profibrotic markers was not accompanied by an increased collagen production or cell proliferation in fibroblasts in the tested time frame.

Conclusion: Overall, prolonged exposure to human-relevant CNT concentrations appears to be a highly suitable approach to predict profibrotic response in vitro.
\end{abstract}

Keywords: acute and prolonged exposures, hazard assessment, in vitro lung cell cultures, multiwalled carbon nanotubes, profibrotic response

\section{Introduction}

D URING THE PAST TWO DECADES, the incorporation of engineered nanomaterials (NMs) in consumer and industrial applications has tremendously increased. ${ }^{1}$ In fact, since 2006, the use of NMs in everyday products has more than quadrupled, subsequently raising public concerns regarding their potential human health effects during the products life cycle. ${ }^{2}$

Among the variety of existing engineered NMs, the extraordinary properties of carbon nanotubes (CNTs), including remarkable tensile strength, thermal stability, and excellent

\footnotetext{
${ }^{1}$ BioNanomaterials, Adolphe Merkle Institute, University of Fribourg, Fribourg, Switzerland.

${ }^{2}$ Laboratory for Materials-Biology Interactions, Empa, Swiss Federal Laboratories for Materials, Science and Technology, St Gallen, Switzerland.

${ }^{3}$ In Vitro Toxicology Group, Swansea University Medical School, Swansea, Wales, United Kingdom.

${ }^{4}$ Department of Chemistry, University of Fribourg, Fribourg, Switzerland.

(C) Savvina Chortarea et al. 2018; Published by Mary Ann Liebert, Inc. This Open Access article is distributed under the terms of the Creative Commons License (http://creativecommons.org/licenses/by/4.0), which permits unrestricted use, distribution, and reproduction in any medium, provided the original work is properly cited.
} 
electrical conductivity, have heightened worldwide commercial interest. ${ }^{3-5}$ However, the expanding use of CNTs has raised concerns, due to their potential biopersistence and high aspect ratio that are similar to specific types of micronsized asbestos fibers. Such concerns were raised from several studies that indicated that exposure to CNTs may be associated with carcinogenic activity in the lung. ${ }^{6-9}$ The potential risk is increased for long, thin fibers with high rigidity as they are able to reach deeper lung regions, where they can remain for extended periods due to impaired macrophage clearance. ${ }^{10-12}$ Indeed, recent in vivo studies reported increased lung injury, inflammation, fibrosis, and granuloma formation, following exposure to long multiwalled CNTs (MWCNTs) $(10-30 \mu \mathrm{m}){ }^{13,14}$ Taken into consideration that human exposure to CNTs is highly possible within occupational, consumer, or environmental setting, there is heightened concern as to the pathogenic potential of CNTs. ${ }^{4}$

One of the most serious consequences of the inhalation of fiber-shaped NMs, and other micron-sized, particulate materials, for example, crystalline silica, is lung fibrosis. ${ }^{15}$ Various in vivo and in vitro studies have investigated the profibrotic potential of MWCNTs; however, contradictory results have been reported. ${ }^{16-21}$ The different findings have been attributed to differences in the mode of exposure, cell models used, preparation of test samples, and dose metrics. Despite the inconsistent conclusions, it has been indicated that MWCNTs physicochemical characteristics, that is, aspect ratio, size, impurities, rigidity, or surface functionalization, as well as dispersion state and doses applied can influence their potential fibrogenic capacity. ${ }^{22-24}$ Therefore, it is of great importance to clearly identify which properties of CNTs can be correlated with such an adverse biological impact.

In the development of lung fibrosis, a key biological event is the activation of fibroblasts, which are the most common cells in the connective tissue. ${ }^{15,25}$ In particular, chronic inflammation or extended tissue injury can result in lung fibrosis as a result of uncontrolled fibroblast proliferation, transformation into myofibroblasts, and increased production of extracellular matrix (ECM) constituents. ${ }^{22,26}$ The effects of CNTs on fibroblasts can be described as related to either a direct or indirect interaction. ${ }^{15}$ Recent in vivo studies provided evidence that welldispersed CNTs can reach the alveolar interstitium, where they can come in contact and directly act on fibroblasts, thus conceivably contribute to fibrosis. ${ }^{13,18}$ On the other hand, CNTs can trigger cells in the frontline of the alveolar tissue barrier, that is, macrophages and epithelial cells, to release proinflammatory and profibrotic mediators, which then in turn indirectly mediate fibroblasts recruitment and activation. ${ }^{27,28}$

The aim of our study was to investigate both the "direct" and "indirect" proinflammatory and profibrotic activity of Mitsui-7 MWCNTs using monocultures (cell lines) of human lung alveolar epithelial cells, macrophages, and fibroblasts, by assessing the biological impact of different MWCNT concentrations on each cell culture type independently. The adverse effects associated with MWCNT exposure have so far mainly been investigated in vitro upon acute exposures (up to 24 hours) to high CNT doses (up to $150 \mu \mathrm{g} / \mathrm{mL}$ ), but the proinflammatory and profibrotic activity of lower, more realistic, and human-relevant concentrations combined with prolonged time periods are not yet described. Therefore, the cellular response at low concentrations (ranging from $5-20 \mu \mathrm{g} / \mathrm{mL}$ ) was evaluated by applying an acute
(24 hours) and prolonged (96 hours) exposure duration. It is hypothesized that the MWCNTs will interact with all cell types, while they might cause different key proinflammatory and profibrotic effects depending on the cell type and the time frame of exposure.

\section{Materials and Methods}

\section{Chemical and reagents}

All chemicals and reagents used were obtained from Sigma-Aldrich (Switzerland), unless otherwise stated.

\section{Cell cultures}

Human alveolar type II epithelial cells. Alveolar epithelial type II A549 cells (ATCC ${ }^{\circledR}$ CCL-185 ${ }^{\mathrm{TM}}$ ) were cultured in Rosewell Park Memorial Institute (RPMI) 1640 medium supplemented with $10 \%$ fetal calf serum (FCS; Gibco, Zug, Switzerland), 1\% L-Glutamine (L-Glut; Life Technologies, Europe, Zug, Switzerland), and 1\% penicillin/streptomycin (P/S) $(10,000$ units $/ \mathrm{mL} / 10,000 \mu \mathrm{g} / \mathrm{mL}$; Gibco, Zug, Switzerland) and maintained at $37^{\circ} \mathrm{C}$ and $5 \% \mathrm{CO}_{2}$. Cells were seeded at a density of $5 \times 10^{5}$ cells/insert in 12-well BD Falcon ${ }^{\mathrm{TM}}$ cell culture inserts $\left(0.9 \mathrm{~cm}^{2}\right.$ growth area, $1.0 \mu \mathrm{m}$ pore size, and high density polyethylene terephthalate [PET] membrane) under submerged conditions (i.e., $1 \mathrm{~mL}$ medium in the apical chamber and $1.5 \mathrm{~mL}$ of medium in the basal chamber) for 3 days.

Human macrophages. Similar to A549 cells, the THP-1 peripheral blood monocyte cell line (ATCC TIB-202 $\left.{ }^{\mathrm{TM}}\right)$ ) was cultured in supplemented RPMI medium with the addition of $0.05 \mathrm{mM} \beta$-mercaptoethanol to avoid cell agglomeration. To differentiate THP-1 monocytes into macrophages, $0.02 \mu \mathrm{M}$ of Phorbol-12-myristate 13-acetate (PMA; Sigma-Aldrich, Switzerland) was added to the cell cultures. Following 24 hours of incubation, $6 \times 10^{4}$ cells/insert were seeded on 12 -well inserts $\left(0.9 \mathrm{~cm}^{2}\right.$ growth area, $1.0 \mu \mathrm{m}$ pore size, high density PET membrane) for 3 days under submerged conditions.

Human lung fibroblasts. The MRC-5 lung fibroblast cell line (ATCC CCL-171 ${ }^{\mathrm{TM}}$ ) was maintained in Minimum Essential Medium (MEM) supplemented with 10\% FCS, $1 \% \mathrm{~L}-$ Glut, $1 \% \mathrm{P} / \mathrm{S}$, and $1 \%$ of MEM nonessential amino acid (Sigma Aldrich, Switzerland) solution at $37^{\circ} \mathrm{C}$ and $5 \% \mathrm{CO}_{2}$. Fibroblasts were seeded in 12-well BD Falcon ${ }^{\mathrm{TM}}$ cell culture inserts at a density of $9 \times 10^{3}$ cells/insert and cultured for 4 days under submerged conditions.

\section{Preparation of MWCNT suspension and control samples}

MWCNTs (Mitsui-7; Mitsui \& Co, Japan) were kindly provided by Prof. Vicki Stone, Heriot-Watt University, Edinburgh, United Kingdom, and used without any further purification. They were dispersed in bovine serum albumin (BSA; $1 \mathrm{mg} / \mathrm{mL}$ in $\mathrm{H}_{2} \mathrm{O}$ ) to obtain a well-dispersed suspension for exposure experiments. Briefly, to prepare the stock suspension, dry MWCNT powder was weighed and heat sterilized overnight at $100^{\circ} \mathrm{C}$. Then, $1 \mathrm{mg} / \mathrm{mL} \mathrm{BSA}$-observed optimal BSA concentration for the dispersion of MWCNTs (data not shown) - was added in the vial and sonicated for an additional 3 hours. The MWCNT suspension was stored at $4^{\circ} \mathrm{C}$, until required for experimentation. Before exposure, the stock suspension was sonicated for 1 hour to disperse 
agglomerates and was then diluted to the working concentrations $(5,10$, and $20 \mu \mathrm{g} / \mathrm{mL})$ in supplemented cell culture medium.

BSA-treated cells (i.e., cells treated with $1 \mathrm{mg} / \mathrm{mL}$ BSA) were used as negative control cultures. To examine the difference in cellular response between different MWCNT types, the biological impact upon cells exposed to short, entangled Nanocyl-7000 MWCNTs (obtained from European Commission Joint Research Centre, ISPRA, Italy; originated from Nanocyl S.A., Belgium) at a concentration of $20 \mu \mathrm{g} / \mathrm{mL}$ was also assessed. The dispersion method for Nanocyl-7000 was the same as for Mitsui-7 MWCNTs. In addition, a reference material for profibrotic response, that is, crystalline silica, Min-USil, was used as positive particle and fibrotic control as various studies have shown that it can cause fibrosis in vivo. ${ }^{29,30} \mathrm{Min}-\mathrm{U}-$ Sil was dispersed in autoclaved ultrapure water to prepare a stock suspension of $1 \mathrm{mg} / \mathrm{mL}$ and sonicated for 1 hour to obtain a well-dispersed suspension. The stock solution was then further diluted to the working concentration of $25 \mu \mathrm{g} / \mathrm{mL}$-an optimal concentration for a continuous 96 hours of exposure, as higher Min-U-Sil concentrations resulted in significant cell death (data not shown)—with supplemented cell culture medium.

\section{Transmission electron microscopy}

To characterize the MWCNTs' dispersed suspensions, $4 \mu \mathrm{L}$ of stock suspension was added on a transmission electron microscopy (TEM) copper grid and left to air dry before visualization by TEM. Representative images of MWCNTs were captured using an FEI Technai Spirit (Oregon), operating at $120 \mathrm{kV}$. Images were recorded with a Veleta CCD camera (Olympus, Japan). The average length and width distribution of suspended MWCNTs were derived from captured TEM images, measuring $\sim 200$ individual CNTs using ImageJ software. ${ }^{31}$

\section{Endotoxin content}

The endotoxin concentration in CNT suspensions was measured using the Pierce ${ }^{\mathrm{TM}}$ LAL Chromogenic Endotoxin Quantitation kit (ThermoFisher Scientific), following the manufacturer's instructions.

\section{Exposure scenarios}

The biological response of different lung cell cultures, following suspension MWCNT (Mitsui-7) exposure, was evaluated at exposure concentrations ranging from 5 to $20 \mu \mathrm{g} / \mathrm{mL}$. The cellular impact was assessed at two exposure scenarios: (i) following acute, continuous MWCNT exposure of 24 hours and (ii) after prolonged 96 hours of continuous exposure. Cells were exposed apically ( $1 \mathrm{~mL}$ of material suspension added to the apical chamber) and kept at $37^{\circ} \mathrm{C}$ in $5 \%$ $\mathrm{CO}_{2}$ throughout each exposure scenario. For the 96-hour exposure strategy, the cell culture medium after 48 hours was aspirated and replaced with fresh cell culture medium containing the test materials, to provide the necessary nutrients for the cell survival under prolonged experimental settings and maintain them at a continuous exposure environment. Of note is that, for the 96-hour exposures, the cell cultures received two repeated doses of the materials under investigation (one dose at the beginning of the experiment [0 hours] and one after 48 hours as described above).

\section{Interaction of MWCNTs with lung cells}

Cytoviva-enhanced dark-field microscopy. To investigate the interaction of Mitsui-7 MWCNTs within the different monoculture types, cells were seeded in detachable fourwell culture slides (BD Falcon; $1.7 \mathrm{~cm}^{2}$; working volume $0.7-1.24 \mu \mathrm{L}$ ) and exposed to 5 and $10 \mu \mathrm{g} / \mathrm{mL}$ (images were not captured at the concentration of $20 \mu \mathrm{g} / \mathrm{mL}$ as the large amount of tubes in the samples was greatly scattering and subsequently resulted in out of focus images) of Mitsui-7 MWCNTs for 24 or 96 hours. At the respective time points, the cell cultures were fixed for 15 minutes in $4 \%$ paraformaldehyde (PFA) in PBS at room temperature and subsequently stored (after $3 \times$ washes with PBS) in PBS at $4^{\circ} \mathrm{C}$ until immunofluorescent staining could occur.

Samples were treated with $0.1 \mathrm{M}$ glycine for 15 minutes and subsequently permeabilized with $0.2 \%$ Triton X-100 for another 15 minutes, all at room temperature. Samples were subsequently stained with rhodamine phalloidin (R-415; Molecular Probes, Life Technologies Europe B.V., Zug; dilution 1:50) and 4',6-diamidino-2-phenylindole (DAPI) (Sigma Aldrich, Switzerland; dilution 1:50) for identification of F-actin cytoskeleton and nucleus, respectively. Coverslips were then placed on top of the microscope slides using Glycergel (DAKO Schweiz AG, Baar, Switzerland). Samples were scanned using a $100 \times$ objective lens (numerical aperture 0.6 and 1.2) in Cytoviva dual mode fluorescence-enhanced dark-field microscopy setup (Cytoviva, Inc., Auburn). ${ }^{32}$

\section{Biochemical analysis}

Cytotoxicity. The release of lactate dehydrogenase (LDH) into the supernatant, a well-known indicator of membrane impairment, ${ }^{33}$ was evaluated using a commercially available LDH diagnostic kit (Roche Applied Science, Mannheim, Germany), according to the manufacturer's protocol. Each sample was tested in triplicate and LDH values were expressed relative to the negative control (BSA-treated cells). Determination of the enzyme activity was performed photometrically by measuring the absorbance at $490 \mathrm{~nm}$ (reference wavelength at $630 \mathrm{~nm}$ ). Cell cultures exposed apically to $0.2 \%$ Triton $\mathrm{X}-100$ for 24 hours were used as a positive control.

\section{Cell morphology}

Laser scanning microscopy. After the respective time points ( 24 or 96 hours), cell cultures were fixed and permeabilized as described above in the Cytoviva analysis section. All antibodies were diluted in $0.3 \%$ Triton X-100 and 1\% BSA in PBS and incubated for 2 hours. Cells were stained with rhodamine phalloidin (dilution 1:50, excitation/emission: 540/ $565 \mathrm{~nm}$ ) and DAPI (dilution 1:50, excitation/emission: 405/ $461 \mathrm{~nm}$ ) for F-actin cytoskeleton and nucleus, respectively. Following antibody incubation, membranes were embedded in Glycergel. Cellular morphology was determined through visualization of samples by using an inverted laser scanning confocal microscope (laser scanning microscopy [LSM] 710 (Axio Observer.Z1, Carl Zeiss, Germany, magnification $63 \times$, numerical aperture 1.4). Image processing was conducted with Imaris 3D restoration software (Bitplane AG, Zurich, Switzerland).

\section{Oxidative stress}

The total amount of reduced glutathione (GSH) in the cell cultures was quantified by using a GSH assay kit (Cayman 
Chemical Company, Ann Arbor), following the supplier's instructions. GSH values are expressed as a ratio to the total amount of protein of each sample, as measured by the Pierce bicinchoninic acid protein assay kit (Pierce Protein research Products; Thermo Scientific, Rockford), according to the manufacturer's guidelines.

\section{Cytokine secretion}

Proinflammatory response. Interleukin (IL)- 8 and IL- $1 \beta$ secretion were assessed using the commercially available DuoSet Enzyme-linked Immunosorbent Assay (ELISA) Development diagnostic kit (R\&D Systems, Switzerland), according to manufacturer's protocol. Cells treated apically with $1 \mu \mathrm{g} / \mathrm{mL}$ of tumor necrosis factor- $\alpha$ for 24 hours served as the positive assay control.

Profibrotic response. Transforming growth factor- $\beta 1$ (TGF- $\beta 1$ ), platelet-derived growth factor-AA (PD-GF), and osteopontin (OPN) released into the supernatant of exposed cells were quantified using the respective ELISA DuoSet Development diagnostic kit, following the manufacturer's protocol. Cell cultures exposed apically to $1 \mu \mathrm{g} / \mathrm{mL}$ of interferon gamma for 24 hours were used as a positive control for TGF- $\beta$; while apical cell treatment with $100 \mathrm{ng} / \mathrm{mL}$ TGF- $\beta$ served as the positive control for both PD-GF and OPN secretion.

\section{Collagen formation}

Collagen production by fibroblasts was quantified using the commercially available Sircol assay (Biocolor Ltd., United Kingdom), following the supplier's instructions. The amount of soluble collagen in the supernatant was examined photometrically by measuring the absorbance at $555 \mathrm{~nm}$. Cells treated apically with TGF- $\beta(100 \mathrm{ng} / \mathrm{mL})$ served as a positive control.

\section{Fibroblast proliferation}

Following 24 or 96 hours of exposure, MRC-5 cells were labeled with BrdU (5-bromo-2'-deoxyuridine) labeling solution and further incubated for 3 hours at $37^{\circ} \mathrm{C}$. Subsequently, cells were washed to remove BrdU solution and fixed in $4 \%$ PFA for 15 minutes. Samples were then prepared according to the manufacturer's protocol (BrdU labeling and detection assay, ThermoFisher Scientific). Membranes were also stained with DAPI for 30 minutes to label cell nuclei. Samples were visualized by confocal microscopy (Zeiss LSM 710), as previously described. Cell counting using imagebased analysis was performed automatically using a selfwritten Matlab script. The percentage of proliferating cells was obtained by dividing the total number of BrdU-stained cells over the total population of cells.

\section{Statistical analysis}

For each data point, three independent experiments $(n=3)$ were performed and all data are presented as the mean \pm standard error of the mean. Statistical analysis was performed using GraphPad Prism 6 (GraphPad Software, Inc., La Jolla) software. A parametric one-way analysis of variance with subsequent Dunnett test was performed. Results were considered significant if $p<0.05$.

\section{Results}

\section{MWCNT characteristics}

MWCNT dispersion (both Mitsui-7 and Nanocyl-7000) in $1 \mathrm{mg} / \mathrm{mL}$ BSA resulted in a well-dispersed CNT suspension. Representative TEM images revealed different morphologies for the two CNT types. Mitsui-7 MWCNTs appear as relatively well-dispersed, small bundles or singlets of long and intermediate-length nanotubes. Nanocyl-7000 suspensions consists of shorter, thinner and highly entangled tubes (Fig. 1A, Supplementary Fig. S1A; Supplementary Data are available online at www.liebertpub.com/aivt). Mitsui-7 suspension revealed an average length of $5.66 \pm 4.7 \mu \mathrm{m}$ and diameter of $60.1 \pm 18.2 \mathrm{~nm}$ (Fig. 1B-D). Notably, the length of Mitsui-7 suspended tubes is considerably shorter, compared to nonsuspended tubes in powder form, as measured by previous studies. $^{8,18}$ It was not possible to determine the size distribution of Nanocyl-7000 in suspension due to their increased agglomeration under these conditions. However, Nanocyl-7000 dry powder has been fully characterized previously (Supplementary Fig. S1), indicating an average length of $4 \pm 0.4 \mu \mathrm{m}$ and diameter of $11 \pm 4 \mathrm{~nm} .^{34,35}$ Endotoxin content of both MWCNT suspensions was found to be below the detection limit. Other key physicochemical characteristics such as metal contaminants for both MWCNT samples are summarized in Figure 1D and Supplementary Figure S1B.

\section{MWCNT-lung cell interaction}

Using fluorescence-enhanced dark-field microscopy, it was possible to visualize the interaction of Mitsui-7 MWCNTs at two concentrations ( 5 and $10 \mu \mathrm{g} / \mathrm{mL}$ ), with the three lung cell cultures (A549, MRC-5, and THP-1 cells) under both exposure scenarios, that is, 24 and 96 hours. It was apparent from a first observation that a concentration-dependent interaction (internalization or attachment to the cellular membrane) was notable with all cell types for each MWCNT type studied. Notably, some THP-1 macrophages showed an increased association with MWCNTs, compared to epithelial or fibroblast cell cultures (Fig. 2A-C, Supplementary Fig. S2A-C), possibly because of their phagocytic activity ${ }^{36}$ in comparison to the other cell types investigated. As shown from the 3D-rendered images, the cellular uptake of single short tubes or small agglomerates occurs in all three cell types, while large agglomerates are mainly attached on the cells surface (Fig. 2A-C).

\section{Cytotoxicity and cell morphology}

Exposure to different Mitsui-7 MWCNT concentrations did not elicit any significant cytotoxic response upon acute (24 hours) or prolonged exposures (96 hours) in any of the tested cell culture types (Fig. 3A). Similarly, no significant cytotoxicity $(p>0.05)$ was observed following exposure to Nanocyl-7000 or Min-U-Sil. Various studies have reported that MWCNTs might interfere with commonly used in vitro biological assays (e.g., cytotoxicity and viability tests). ${ }^{37}$ Therefore, in this study, NM suspensions were evaluated for potential interference with the assays used and no interference was detected at the tested concentrations (Supplementary Fig. S3).

No alterations in cellular morphology were observed by LSM in A549 epithelial cells treated with 5 and $10 \mu \mathrm{g} / \mathrm{mL}$ of Mitsui-7 MWCNT for 24 hours, compared to negative control cultures. However, A549 cells exposed to the highest 


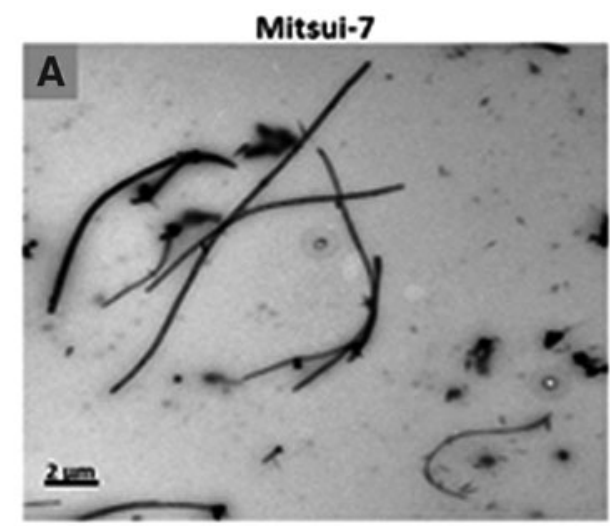

Size distribution of Mitsui-7 MWCNTs
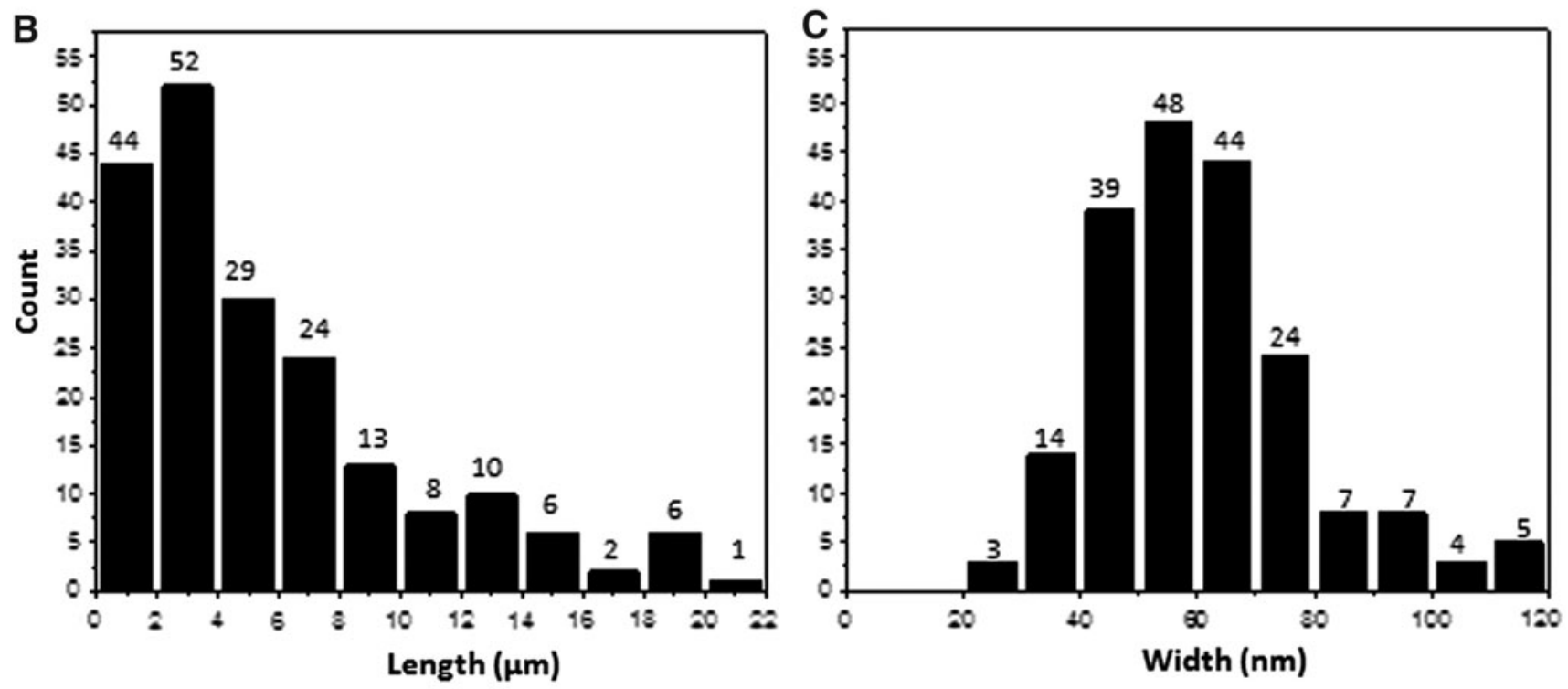

\begin{tabular}{ccc}
\hline MWCNTs (Mitsui-7) & powder & suspension \\
\hline Length $(\mu \mathrm{m})$ & $13^{8,18}$ & $5.66 \pm 4.7$ \\
Width $(\mathrm{nm})$ & $84.89 \pm 1.9^{8,18}$ & $60.1 \pm 18.2$ \\
\hline $\begin{array}{c}\text { Other MWCNT Mitsui-7 characteristics: } \\
\text { Elemental Contaminants }(\mu \mathrm{g} / \mathrm{g})\end{array}$ & $\mathrm{Fe}(\mathrm{ND}), \mathrm{V}(0.8), \mathrm{Ni}(6.2), \mathrm{Co}(1.9) \mathrm{Cu}(1.2)^{8,18}$ \\
\multicolumn{2}{c}{ Endotoxin Content } & ND \\
\hline
\end{tabular}

FIG. 1. Morphology, size distribution, and physicochemical characteristics of Mitsui-7 MWCNTs. (A) Transmission electron microscopy image of MWCNT stock suspension. Histogram represents the (B) length (in $\mu \mathrm{m})$ and (C) width (in nm) distribution, respectively, of dispersed Mitsui-7 MWCNTs. (D) The table summarizes the key physicochemical characteristics of Mitsui-7 MWCNTs. ND, not detectable; MWCNTs, multiwalled carbon nanotubes.

Mitsui-7 concentration $(20 \mu \mathrm{g} / \mathrm{mL})$ revealed slight alterations to cellular morphology after 24 hours, which became more pronounced after 96 hours of exposure (Fig. 3B and Supplementary Fig. S4A). In fact, after acute (24 hours) exposure to $20 \mu \mathrm{g} / \mathrm{mL}$ of Mitsui-7, the epithelial cells started to disorganize, losing cellular contacts. Furthermore, following long-term (96 hours) treatment, the cells lost their regular cu- boidal shape, showing either rounded or a spindle-like appearance. Morphological changes were not observed in THP-1 macrophages or MRC-5 fibroblasts following 24 hours of Mitsui-7 MWCNT exposure (Fig. 3B), but prolonged 96 hours of exposure resulted in an apparent alteration in F-actin cytoskeleton staining in both macrophages and fibroblasts, when compared to negative control cultures, 
FIG. 2. MWCNT-lung cell interaction upon acute MWCNT exposure. Fluorescence-enhanced dark-field microscopy images of (A) A549, (B) THP-1, and (C) MRC-5 cells exposed to 5 and $10 \mu \mathrm{g} / \mathrm{mL}$ of Mitsui-7 MWCNTs for 24 hours. Magenta color shows F-actin (cytoskeleton), blue color represents DNA (cell nuclei), and green color shows Mitsui7 MWCNTs. White arrows point out the internalized MWCNTs.
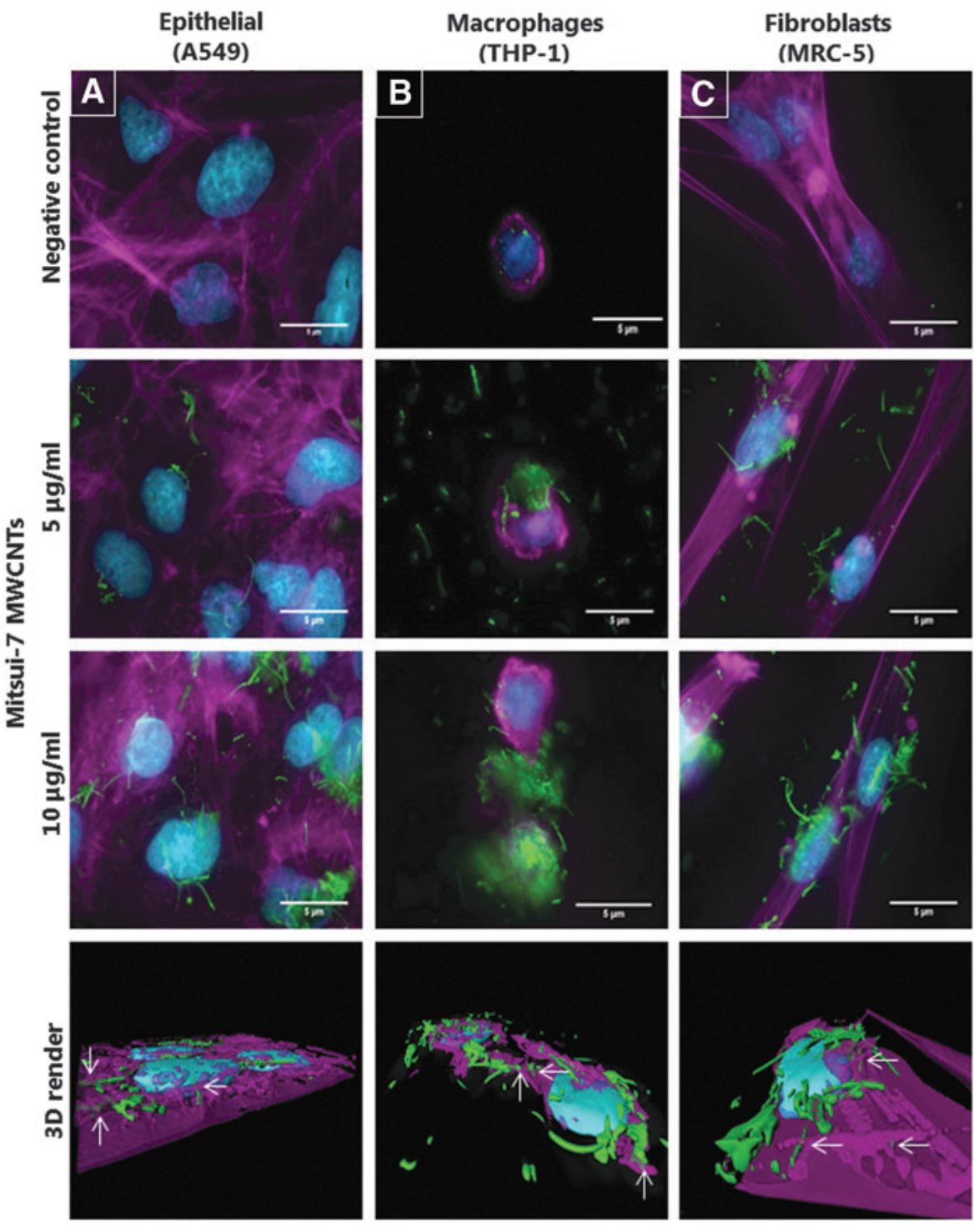

thus indicating an impact on these cell types upon extended exposure time frames (Supplementary Fig. S4B-C).

\section{Oxidative stress response}

Total GSH content was assessed as an important marker for oxidative stress. ${ }^{38}$ Both epithelial and fibroblast cell lines showed a slight loss in intracellular GSH levels at $20 \mu \mathrm{g} / \mathrm{mL}$ of Mitsui-7 following 24 hours of exposure (Fig. 4A and $\mathrm{C}$ ). At the same time point, macrophages showed a notable decrease (not statistically significant) in GSH at both 10 and $20 \mu \mathrm{g} / \mathrm{mL}$ of Mitsui-7 (Fig. 4B). Following 96 hours of exposure, a decrease (not statistically significant) of GSH was observed in both A549 epithelial and THP-1 macrophage cell cultures at all Mitsui-7 concentrations tested. Acute 24 hours of exposure to Nanocyl-7000 MWCNTs resulted in decreased GSH in all cell culture types (significant for MRC-5 cells, $p<0.05$ ). Similarly, a decrease in GSH was observed at the 96-hour time point in epithelial cells only, while no effect was shown in Nanocyl7000 exposed MRC-5 or THP-1 cells. At 24 hours, Min-USil induced a clear effect in intracellular GSH content in both fibroblast $(p<0.05)$ and macrophage cultures. Prolonged exposure to Min-U-Sil led to GSH reduction in epithelial and macrophages cells, although not significant $(p>0.05)$ when compared to the negative controls.

\section{Proinflammatory response}

Acute or prolonged exposures to different concentrations of Mitsui-7 did not induce any significant effect on the level of secreted IL-8 in any of the tested cell types (Fig. 5A-C). IL8 levels were increased in Nanocyl-7000 exposed A549 and THP-1 cells at 96 hours, although this increase was not statistically significant compared to negative control. IL-8 secretion appeared to be increased, in A549 cells following either 24 or 96 hours of exposure to Min-U-Sil, but it was not determined to be statistically significant.

THP-1 cells have been successfully used to investigate the proinflammatory effect of MWCNTs and other high aspect ratio materials, for example, asbestos fibers and nanowires, on the induction of IL- $1 \beta$ secretion. ${ }^{39}$ The synergy between IL- $1 \beta$ release and TGF- $\beta$ production plays a crucial role in excess collagen production and deposition in the lung. ${ }^{40,41}$ 

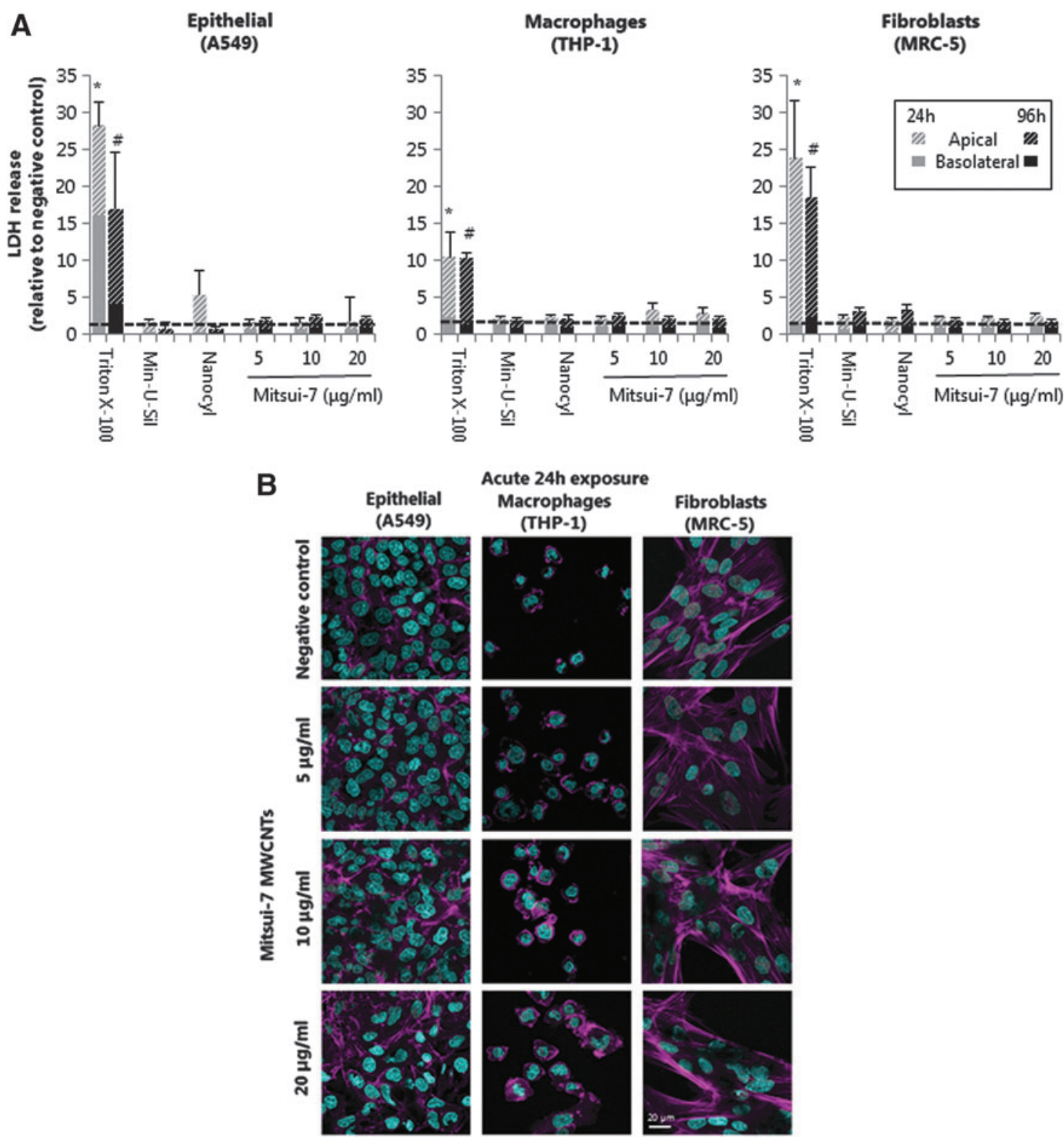

FIG. 3. Cytotoxicity and cellular morphology of MWCNT-exposed lung cell cultures following 24 and 96 hours of exposure. (A) Cytotoxicity as estimated by quantification of LDH release in cell culture medium in A549 epithelial, THP-1 macrophage, and MRC-5 fibroblast cell lines. Data are presented as the mean \pm SEM relative to negative control. Dashed line represents the level of negative control. *Represents a significant increase $(p<0.05)$ compared to the negative control at 24-hour time point. \#Indicates statistical significance in lung cultures at 96 hours, compared to the negative control $(p<0.05)$. (B) LSM images of cells following acute (24 hours) Mitsui-7 MWCNT exposure. Blue color shows the DNA (cell nuclei) and pink color shows the F-actin cytoskeleton. LSM, laser scanning microscopy; SEM, standard error of the mean.

Notably, a statistically significant IL- $1 \beta$ release $(p<0.05)$ was observed in fibroblasts exposed to the lowest Mitsui-7 dose $(5 \mu \mathrm{g} / \mathrm{mL})$ at the 24-hour time point, however, not for the higher concentrations in both 24- and 96-hour scenarios, compared to control cultures (Fig. 5C). At the same time point, THP- 1 cells also showed significant IL- $1 \beta$ secretion at $5 \mu \mathrm{g} /$ $\mathrm{mL}(p<0.05$; Mitsui-7), as well as an apparent, but statistically insignificant, increase at $20 \mu \mathrm{g} / \mathrm{mL}$ (Mitsui-7). Prolonged 96 hours of exposure at the lowest dose $(5 \mu \mathrm{g} / \mathrm{mL})$ of Mitsui7 also elicited notable IL- $1 \beta$ release; however, this increase was not found to be statistically significant. Prolonged expo- sure to Min-U-Sil resulted in a statistically significant IL- $1 \beta$ ( $p<0.05$; 96 hours) release in THP-1 macrophages.

\section{Profibrotic response}

Recent studies have shown that TGF- $\beta$ released by alveolar epithelial cells and macrophages contributes to the pathogenesis of pulmonary fibrosis (in synergy with IL- $1 \beta$ induction); therefore, the secretion of TGF- $\beta$ levels in the supernatant was assessed in the tested cell types. ${ }^{41}$ Acute exposures to 5,10 , or $20 \mu \mathrm{g} / \mathrm{mL}$ Mitsui-7 MWCNT concentrations for 24 hours did 

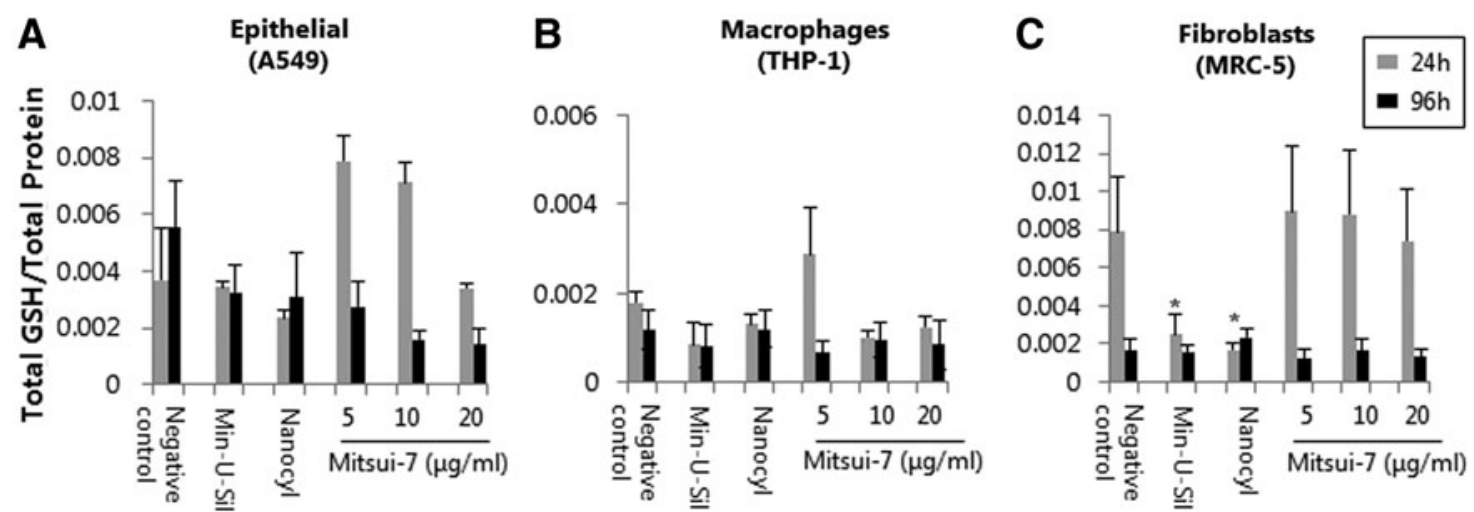

FIG. 4. Cellular response to oxidative stress upon acute or prolonged exposure to different concentrations of Mitsui-7 MWCNTs. GSH levels in (A) A549, (B) THP-1, and (C) MRC-5 monocultures after 24-hour (gray) and 96-hour (black) exposures to MWCNTs and the controls. Data are presented as the mean \pm SEM of at least three independent experiments. Values were considered significantly different compared to the negative control (BSA-treated cells) with $p<0.05(* 24-$ hour exposure). BSA, bovine serum albumin; GSH, glutathione.

not induce TGF- $\beta$ release in any of the tested cell types compared to the negative control. Importantly, however, prolonged 96-hour exposure to the same Mitsui-7 concentrations elicited a statistically significant TGF- $\beta$ secretion in both A549 and MRC-5 cells (but not in THP-1 cells) (Fig. 6A and $\mathrm{C}$ ). In contrast, Nanocyl-7000 exposure for 24 hours and Min-U-Sil for both 24 and 96 hours resulted in a significant increase in TGF- $\beta$ protein levels $(p<0.05)$ in A549 (Fig. 6A) and MRC-5 cultures (Fig. 6C).
PD-GF levels were not altered after 24 hours of exposure to Mitsui-7 in any of the tested cell types and only Nanocyl7000 and Min-U-Sil induced a significant effect in fibroblasts after 24 hours. However, prolonged ( 96 hour) Mitsui- 7 exposure induced elevated PD-GF secretion in A549 and MRC-5 cells (statistically significant only for A549 cells at all tested concentrations; Fig. 6).

Mitsui-7 exposure in fibroblasts for 24 hours elicited OPN release at the lowest $(5 \mu \mathrm{g} / \mathrm{mL} ; p<0.05)$ and highest $(20 \mu \mathrm{g} / \mathrm{mL})$
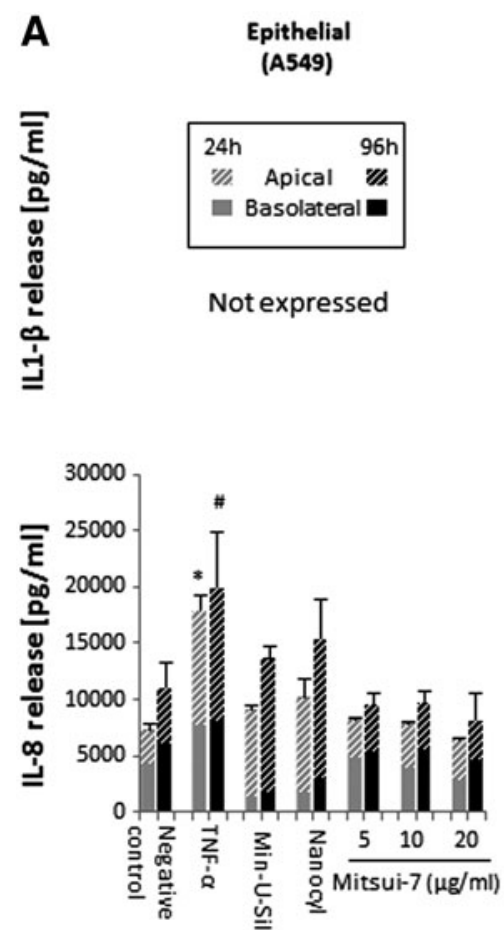
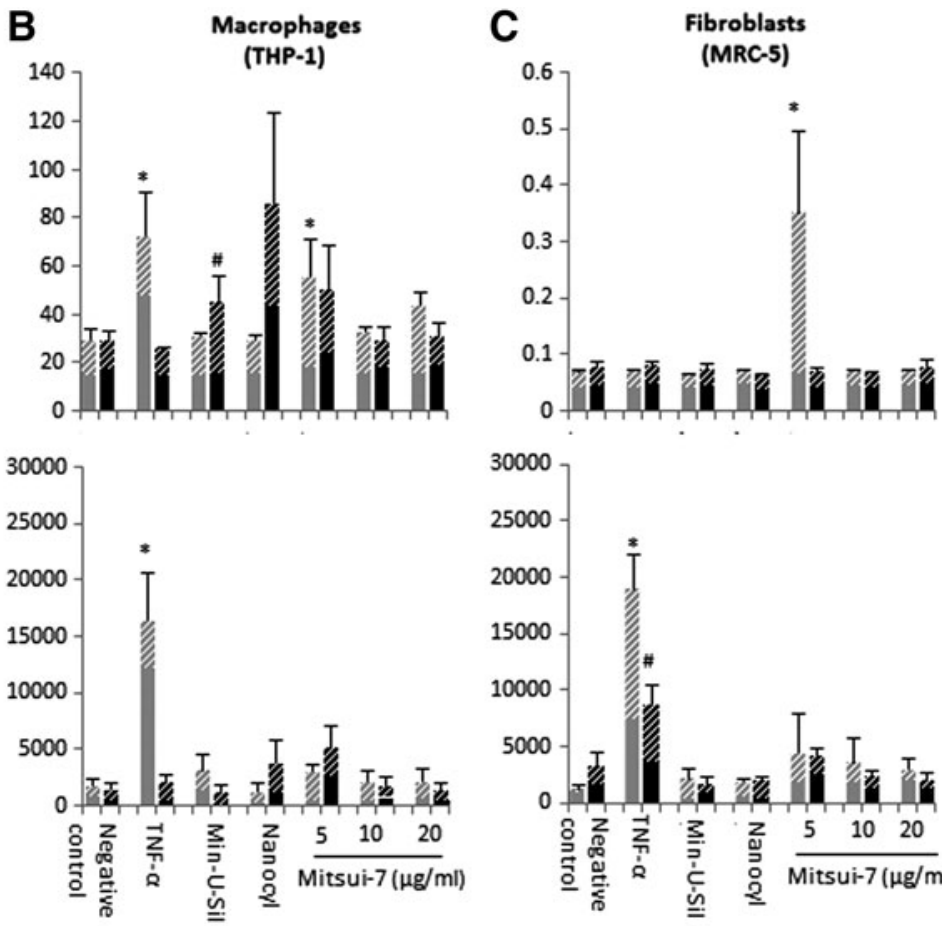

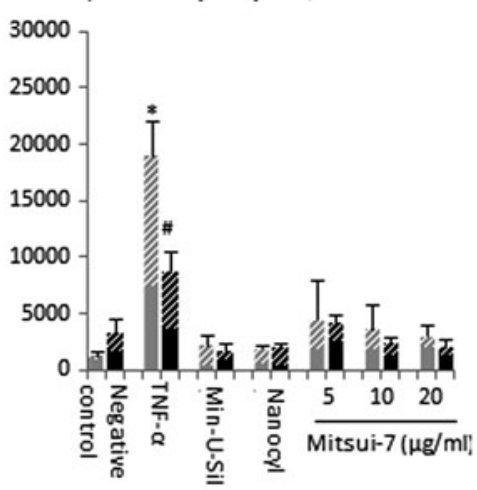

FIG. 5. Proinflammatory response in human lung cultures exposed to different concentrations of Mitsui-7 MWCNTs for up to 96 hours. Quantification of total Interleukin 1-beta (IL-1 $\beta$ ) and IL-8 secretion in (A) A549 epithelial, (B) THP-1 macrophage, and (C) MRC-5 fibroblast cell lines upon 24- or 96-hour exposures. *Represents a significant increase $(p<0.05)$ compared to the negative control at 24-hour time point. \#Indicates statistical significance in lung cultures at 96 hours, compared to the negative control $(p<0.05)$. 

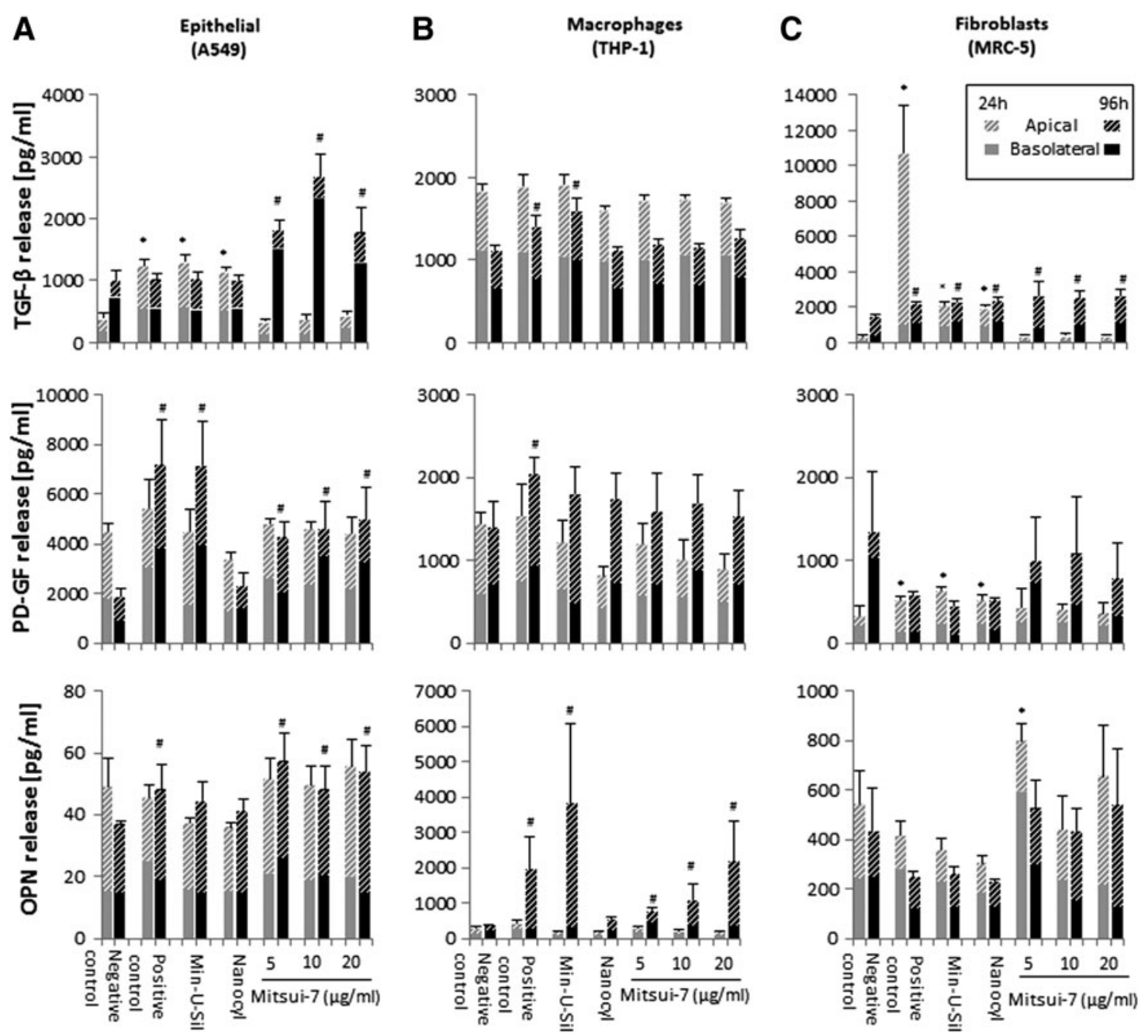

FIG. 6. Profibrotic response of MWCNT-exposed lung cell cultures, following acute or prolonged exposure. TGF- $\beta$, PDGF, and OPN secretion in (A) A549, (B) THP-1, and (C) MRC-5 cell cultures after 24- and 96-hour exposure to different concentrations of Mitsui-7 MWCNTs. Interferon-gamma $(1 \mu \mathrm{g} / \mathrm{mL})$ was used as a positive control for TGF- $\beta$ and TGF- $\beta$ $(100 \mathrm{ng} / \mathrm{mL})$ was used as positive control for PD-GF and OPN induction, respectively. *Represents a significant increase $(p<0.05)$ compared to the negative control at 24 -hour time point. \#Indicates statistical significance in lung cultures at 96 hours, compared to the negative control $(p<0.05)$. TGF- $\beta$, total transforming growth factor- 1 ; PD-GF, platelet derivedgrowth factor-AA; OPN, osteopontin.

concentrations tested. Of note, A549 (Fig. 6A) and THP-1 (Fig. 6B) cells showed a statistically significant $(p<0.05)$ OPN release at the 96-hour time point following exposure to 5,10 , or $20 \mu \mathrm{g} / \mathrm{mL}$ Mitsui-7. Min-U-Sil induced a statistically significant $(p<0.05)$ OPN response after 96 hours in macrophages, but not in the other two cell types tested.

Finally, the differential secretion of markers observed in the apical and basolateral compartment can be attributed to the relative small pore size $(1 \mu \mathrm{m})$ of the inserts, which might reduce the diffusion speed of markers from the apical to the basal side.

\section{Fibroblast activation}

Activation of fibroblasts (MRC-5 cell line) after exposure to MWCNTs was investigated by quantifying the levels of soluble collagen production and by observing cell proliferation. No significant changes were observed in collagen production in fibroblasts exposed to Mitsui-7 at both 24- and 96-hour time points, compared to the negative control (Supplementary Fig. S5A). A slight increase in collagen levels was only seen in cells exposed to highest concentration of Mitsui-7 $(20 \mu \mathrm{g} / \mathrm{mL})$ for 24 hours, although not statistically significant $(p>0.05)$. Only exposure to Min-U-Sil induced a significant increase $(p<0.05)$ in collagen production after 96 hours.

Proliferating fibroblasts were visualized for all tested concentrations in both acute and prolonged exposure scenarios (Supplementary Fig. S5C). Semiquantitative image-based analysis using BrdU staining of fibroblasts demonstrated a decrease in the percentage of proliferating cells in Mitsui-7-exposed cells compared to the negative control cultures at both 24 and 96 hours of exposure (Supplementary Fig. S5B). Interestingly, cells surrounded by large Mitsui-7 agglomerates did not show any signs of proliferation (data not shown), indicating that such cellular interaction with large MWCNT agglomerates might lead to possible cytostasis. A summary of the biological 
effects induced by acute or prolonged continuous exposure to Mitsui-7 in the different tested cell types is shown in Supplementary Table S1.

\section{Discussion}

Commercial and industrial interest worldwide in the unique properties and multiple applications of CNTs has led to a heightened increase in their production rate, concomitantly raising concerns as to their potential human health effects during their life cycle. ${ }^{5,42}$ Data obtained from in vivo and in vitro studies indicated that exposure to CNTs of specific physicochemical characteristics (i.e., long length and high rigidity) by inhalation can be associated with adverse effects such as pulmonary fibrosis similar to those induced by asbestos fibers. ${ }^{8,43,44}$ While several studies have investigated the biological impact of CNTs in vitro after acute exposures (up to 48 hours) using relatively high CNT concentrations (up to $100 \mu \mathrm{g} / \mathrm{mL}$ ), the knowledge of extended exposure periods to lower, occupationally relevant concentrations is limited. Therefore, our aim was to evaluate the profibrotic potential of two MWCNT forms (Mitsui-7 and Nanocyl-7000) and crystalline silica (as a positive particle control), following either acute or prolonged exposure to three lung cell types relevant to the development of fibrosis. The two types of MWCNTs were chosen because of the differences in their physicochemical properties, for example, Mitsui-7 are longer and more rigid in comparison to Nanocyl-7000. Such properties have been previously shown to impact the toxicological outcomes of exposure to MWCNTs. ${ }^{22}$

In this study, the cell cultures were exposed to sublethal concentrations of MWCNTs $(5-20 \mu \mathrm{g} / \mathrm{mL})$. Such concentrations have been recommended by Borm et al. and Gangwal et al. ${ }^{45,46}$ For instance, the alveolar mass retention of CNTs was modeled and calculated in the range of $12.4-46.5 \mu \mathrm{g} /$ $\mathrm{cm}^{2}$ during 45 years of a working lifetime exposure. ${ }^{46}$ The behavior of Mitsui-7 (BSA-dispersed) in culture medium was recently resolved by using several analytical and imaging techniques. In particular, Septiadi et al. determined the delivered dose profile of Mitsui-7 in vitro following up to 48 hours of exposure using UV-Vis-NIR spectroscopy, optical imaging, and quartz crystal microbalance measurements. By monitoring the depletion profile of MWCNTs in cell culture media, it was confirmed that $\sim 70 \%$ of CNTs sediments on the bottom of the well, while the remaining was dispersed in the medium (Septiadi et al., under review). Moreover, it is important to note that in the 96-hour scenario, the applied MWCNT concentrations were two fold higher than the dose of 24-hour time frame as the medium-MWCNT suspension was refreshed (after 48 hours of continuous exposure). However, according to the dosimetry findings above, a considerable amount of CNTs underwent sedimentation, and thus directly interacted with the cell cultures. Considering the cell growth area of $0.9 \mathrm{~cm}^{2}$ and the sedimentation rate, the final delivered dose of Mitsui-7, as described herein, to the cell cultures is in the range of $3.5-15.3 \mu \mathrm{g} / \mathrm{cm}^{2}$. This represents 3 months to 45 years of the human occupational exposure to MWCNTs as previously described. ${ }^{44,46}$ The authors note, however, that the dose herein was applied over only a 96hour period in vitro.

Studies have shown an indirect and a direct mechanism leading to lung fibrosis. ${ }^{15,30}$ MWCNTs can induce lung fi- brosis through the indirect pathway, which is mainly mediated by macrophages and epithelial cells that represent the cellular frontline of the alveolar region and release mediators, subsequently activating fibroblasts located in the underlying interstitium. ${ }^{15}$ In contrast to the indirect mechanism, growing evidence confirms that CNTs can rapidly reach the alveoli and directly act on fibroblasts, thus leading to fibrosis. ${ }^{13}$ Therefore, in this study, the three most representative cell types involved in the indirect and direct pathogenesis mechanism of fibrosis were selected and their profibrotic activity upon different MWCNT concentrations was examined. The importance of the selected cell types has been further verified by Vietti and collegues, who suggested that an adverse outcome pathway for CNT-induced fibrosis should include the chosen panel of cell cultures. ${ }^{15}$ The rational to use monocultures was (i) to evaluate if the different cell types, which are relevant for the onset of fibrosis, can be used under prolonged time periods and (ii) if lower, more realistic concentrations of MWCNTs can induce proinflammatory and/or profibrotic responses.

The Mitsui-7 MWCNTs used in this study are long with length of up to $30 \mu \mathrm{m}$, have high rigidity and stiffness, and have recently been classified as potentially carcinogenic to humans (IARC, Group 2B). ${ }^{47}$ Recent in vivo studies indicated that Mitsui-7 promote inflammatory and fibrotic effects, as well as cause the onset of peritoneal mesothelioma upon single intratracheal administration or intraperitoneal injection. $8,48,49$ Nanocyl-7000, another type of MWCNTs, has also been evaluated in this study, and in contrast to Mitsui-7, has been associated with low fibrotic activity in animal models. ${ }^{19,50}$ Despite the substantial number of in vivo tests conducted to investigate respiratory effects of Nanocyl-7000, information about its fibrotic effects on in vitro cell cultures remains limited.

CNTs are highly hydrophobic materials, thus their agglomeration in aqueous solution is inevitable. ${ }^{51}$ Several studies reported that the dispersion state of CNTs as well as the type of dispersant used can influence the MWCNT-induced cellular responses and, in particular, potential fibrotic reactions. ${ }^{4,52}$ In this study, MWCNTs were dispersed in BSA, a protein that has been also recommended by other studies as a useful dispersant, since it has no impact on cell survival or proliferation. ${ }^{30,53}$ Indeed, BSA resulted in a welldispersed MWCNT suspension. Notably, TEM images displayed the extensive morphological differences between the two MWCNT types studied. Mitsui-7 appeared as singlets or bundles of "needle like", with a rigid shape, while the shorter Nanocyl-7000 consisted of highly entangled agglomerated tubes. Size distribution of Mitsui-7 revealed a significantly shorter average tube length compared to the length reported by Poland et al., ${ }^{8}$ possibly due to CNT fracture during the sonication process. However, about $40 \%$ of the tubes had length greater than $5 \mu \mathrm{m}$ and $\sim 10 \%$ of the fibers were longer than $12 \mu \mathrm{m}$. This observation is in agreement with recent in vitro studies, where $2 \%$ mouse serum and $0.1 \%$ Tween-80 were used as dispersants for Mitsui-7. ${ }^{54,55}$ Both studies showed a similar average length $(5-6 \mu \mathrm{m})$ for the same type of MWCNTs after sonication. In fact, Schinwald et al. demonstrated that silver nanowires longer than $5 \mu \mathrm{m}$ are suggested as the threshold length for macrophage impairment and lung inflammation in mice studies. ${ }^{56}$

Visualization of the cells revealed an evident association of Mitsui-7 with all the tested cell types. Single CNTs or small 
agglomerates were internalized by the cells, while large agglomerates strongly interacted with the outer cell membrane. Macrophages had a greater intensity of interaction with both MWCNT types studied, compared to both the epithelial cells and fibroblasts. This finding, however, could be easily attributed to the enhanced phagocytic capacity of macrophages. Similar to our findings, Septiadi et al. also showed that small deposited fractions of Mitsui-7 were partly or fully internalized by A549 cells (Septiadi D, Rodriguez-Lorenzo L, Balog S, et al. In vitro dosimetry of carbon nanotubes. Manuscript under review, 2018). Unlike previous studies that showed that MWCNTs might lead to cytotoxicity, no cytotoxicity was observed for all materials and cell types tested in this study. This difference in the cytotoxicity could be attributed to the fact that in previous studies, extremely high MWCNT concentrations $(100-150 \mu \mathrm{g} / \mathrm{mL})$ have been used. ${ }^{57-59}$ Although no significant modifications were observed in epithelial cells following acute exposure to Mitsui-7, epithelial cultures did show significant altered morphology at the highest MWCNT concentration $(20 \mu \mathrm{g} / \mathrm{mL})$, at 96 hours. In fact, notable disorganization of the F-actin cytoskeleton with subsequent loss of the monolayer morphology was observed as a result of prolonged MWCNT treatment. In line with our observations, Polimeni et al. demonstrated similar effects in BEAS-2B bronchial epithelial cell morphology following 96 hours of exposure to Mitsui-7 MWCNTs ${ }^{53}$ Similarly, we have shown that macrophages and fibroblasts displayed a clear decrease in the visualized F-actin cytoskeleton expression, only following extended continuous Mitsui-7 MWCNT exposure.

In the CNT safety assessment, several in vitro observations consistently demonstrated oxidative stress as the predominant mechanism of the CNT-induced toxicity. Importantly, in vivo studies have confirmed that exposure to CNTs results in oxidative stress in animal tissues as shown by alterations in both GSH and heme-oxygenase-1 levels. ${ }^{60,61}$ Oxidative stress has been also established as the key initiating event in the development of fibrosis, as it promotes fibroblast to myofibroblast transformation and activation by interacting with the TGF- $\beta 1$ signaling pathway, and thus triggers the expression and secretion of the critical profibrotic mediator TGF- $\beta .{ }^{62-64}$ Oxidative stress reactions, as measured by either free radical formation or a loss in antioxidant capacity, have been widely reported in CNT-exposed epithelial cells in various in vitro studies. ${ }^{65,66}$ In our study, we did not observe a statistically significant increase in oxidative stress for any of the treatment groups. However, A549 epithelial cells have shown signs of oxidative stress after prolonged Mitsui-7 exposure, which was more evident for the two highest concentrations ( 10 and $20 \mu \mathrm{g} / \mathrm{mL}$ ) tested. In addition, THP-1 macrophages displayed a depletion of reduced GSH after both 24- and 96-hour time frames. An explanation for the increased loss in reduced GSH in macrophages could be that cells might undergo frustrated phagocytosis, while trying to engulf long MWCNTs, in turn secreting this protein readily during this cellular phenomenon, since inefficient phagocytosis has been related with increased reactive oxygen species (ROS) production in an earlier report. ${ }^{67}$

Numerous in vitro and in vivo studies have suggested that MWCNTs can induce lung fibrosis, although several molecular mechanisms, including increased oxidative stress, enhanced release of proinflammatory and profibrotic mediators in lung cells. ${ }^{68,69}$ Among the proinflammatory cytokines, IL-1 $\beta$ has been shown to play a leading role in the development of fibrosis. Lysosomal damage in macrophages due to MWCNT treat- ment can trigger IL- $1 \beta$ by inducing the assembly of the NLRP 3 (NOD-like receptor family, pyrin domain containing-3) inflammasome, which is responsible for the cleavage of proIL-1 $\beta$ to active IL-1 $\beta .^{40}$ Upregulated IL- $1 \beta$ can act in cooperation with the epithelial- and macrophage-produced profibrotic TGF- $\beta$ to promote epithelial-mesenchymal transition, which results in fibroblast accumulation and subsequently elevated collagen deposition in the lung. ${ }^{38,40}$ Our data show that exposure to $5 \mu \mathrm{g} / \mathrm{mL}$ Mitsui-7 induced a significant IL- $1 \beta$ increase in both macrophages and fibroblasts after 24 hours, while A549 cells did not express this cytokine. Then, IL- $1 \beta$ secretion slightly decreased, but remained elevated in macrophages at 96-hour time point, suggesting constant cell stimulation, which could be associated with increased oxidative stress. The elevated IL-1 $\beta$ release at the lowest Mitsui-7 dose tested can be explained from the fact that at low doses, MWCNTS may be less agglomerated, and thus easily attach to the surface and penetrate the cellular membrane. Similar observations were shown by Fu et al. at low doses of graphene oxide particles, although not at high doses. ${ }^{70}$ Recently, Hamilton et al. reported that MWCNTs could elicit the release of IL- $1 \beta$ in THP- 1 cells. ${ }^{71}$ Similarly, various in vitro studies have shown enhanced IL- $1 \beta$ levels in different macrophage cell lines exposed to CNTs by oxidative stress, nuclear factor-kappa B, and inflammasome activation. ${ }^{69,72}$ Furthermore, IL-1 $\beta$ can trigger the secretion of key profibrotic proteins, that is, TGF$\beta$ and PD-GF, by different lung cell types, emphasizing the importance of the intercellular communication through the release of proinflammatory mediators by macrophages. ${ }^{69}$

IL-8 is another important proinflammatory mediator, mainly associated with acute inflammation. In this study, we did not observe a statistically significant increase in IL-8 protein levels in any of the cell types tested. However, we observed a slight increase in IL-8 in THP-1 and fibroblast cells at the lowest Mitsui-7 concentration, following acute exposure. Similarly, long MWCNTs $(50 \mu \mathrm{g} / \mathrm{mL})$ did not induce IL-8 release in primary alveolar type I and type II cells, while elicited significant response in alveolar macrophages. ${ }^{57}$ Murphy et al. also reported increased IL-8 release in Mitsui-7 $(5 \mu \mathrm{g} / \mathrm{mL})$-exposed THP-1 cells, possibly due to frustrated phagocytosis. ${ }^{73}$

Mitsui-7 were found to significantly increase TGF- $\beta$ and PD-GF secretion into the supernatant of exposed epithelial cells after 96 hours. Both proteins are crucial profibrotic markers in the pathogenesis of pulmonary fibrosis. In particular, TGF- $\beta$ produced by epithelial cells or macrophages has been recognized as the most crucial endogenous regulator of the differentiation of mesenchymal cells and collagen synthesis, as it directly manages the de novo expression of $\alpha$ smooth muscle actin and the production of ECM proteins i.e., collagen and fibronectin. ${ }^{64}$

Furthermore, PD-GF is a potent mitogen for cells of a mesenchymal origin, including fibroblasts. ${ }^{74}$ Increased PD-GF boosts fibroblast proliferation and their differentiation into myofibroblasts, aggravating fibrosis. ${ }^{69}$ Several in vitro studies have shown increased TGF- $\beta$ as well as PD-GF activity following MWCNT exposure. ${ }^{30,68,69}$ However, it is worth to mention that most of the studies examining the role of epithelial cells in pulmonary fibrosis have been performed mainly on bronchial epithelial cell cultures and only limited studies investigated the function of the alveolar epithelium. ${ }^{15}$ Furthermore, both in vivo and in vitro studies have shown the secretion of TGF- $\beta$ and PD-GF from macrophages treated 
with MWCNTs. $^{27,75}$ Similarly, elevated PD-GF and a slight increase in TGF- $\beta$ were observed after 96 hours of Mitsui-7 exposure in THP- 1 cells. This induction of IL- $1 \beta$, TGF- $\beta$, and PD-GF by exposed macrophages further advocates their indirect effects on fibroblasts and potentially contributes to the pathogenesis of MWCNT-induced pulmonary fibrosis.

MWCNTs can also induce the release of TGF- $\beta$ directly from fibroblasts. ${ }^{64} \mathrm{He}$ et al. observed upregulation of TGF$\beta$ and PD-GF in fibroblasts after 24 hours of exposure to $20 \mu \mathrm{g} / \mathrm{mL}$ MWCNTs. ${ }^{69}$ The herein presented data also indicated release of the same growth factors in fibroblasts upon acute exposure to Nanocyl-7000, but not Mitsui-7. Significant TGF- $\beta$ release was demonstrated in Mitsui-7-treated fibroblasts only in the prolonged experimental approach, which clearly attributes the difference in how rapid the profibrotic response occurs between different CNT types.

The release of the profibrotic marker OPN by mouse macrophages after acute ( 24 hours) in vitro exposures to Mitsui- 7 and Nanocyl-400 MWCNTs was recently reported. ${ }^{54} \mathrm{OPN}$ is primarily implicated in fibroblast proliferation as well as in fibroblast migration and formation of ECM. ${ }^{30}$ In particular, increased OPN secretion was measured in mice 2 months after MWCNT pharyngeal aspiration. ${ }^{30}$ Hussain et al. recently determined that conditioned medium from MWCNT-exposed human bronchial epithelial cells could result in increased OPN activity in human lung fibroblasts, highlighting the importance of epithelial-derived mediators in fibrotic reactions. ${ }^{28}$ Similarly, in this study, both epithelial A549 cells and THP-1 macrophages exhibited significant increase in OPN levels mainly after prolonged treatments to different Mitsui-7 concentrations $(5,10$, and $20 \mu \mathrm{g} / \mathrm{mL})$. OPN release was also observed in Mitsui-7-exposed fibroblasts after both acute and prolonged exposures.

Although Mitsui-7 MWCNT exposure increased TGF- $\beta$ and OPN release in MRC-5 fibroblasts upon prolonged exposure, no increase in collagen production was observed. This is in accordance with the cellular proliferation data since proliferation was not increased in MWCNT-exposed cells. This observation might have two possible explanations. It could suggest either that such effects might require a longer postincubation time than the 96 hours used in this study or that the increased cell surface coverage by MWCNTs observed in the prolonged time point might, by some means, block fibroblast activation. On the contrary, Wang et al. showed that exposure to long and entangled MWCNTs $(5 \mu \mathrm{g} / \mathrm{mL})$ for 48 hours induced fibroblast proliferation and collagen production in human CRL1490 fibroblasts. ${ }^{76}$ Another study confirmed the stimulation of cell proliferation in different fibroblast human and mouse cell lines (HFL-1, BALB-3T3, and MLg) following a 24-hour exposure to short MWCNTs (0.7-3 $\mu \mathrm{m}$ length) at $37.5 \mu \mathrm{g} / \mathrm{cm}^{2}$ concentration. $^{30}$ The discordance may be explained by the use of different CNT types, dispersion methods, cell lines, or test concentrations. In particular, depending on the physicochemical properties among different types of MWCNTs, their oxidative stress potential and their fibrotic response appear to vary considerably. ${ }^{15}$

A previous animal study provided evidence that Nanocyl7000 MWCNTs elicited strong acute-phase inflammatory response after intratracheal administration in mice. ${ }^{35}$ Durable interstitial and granulomatous inflammation were also observed in animal lungs after 90 days of inhalation exposure to Nanocyl-7000. ${ }^{19,50}$ In line with those findings, our data showed a pronounced IL- $1 \beta$ release in macrophages as well as a notable IL- 8 release in both epithelial and macrophage cultures after prolonged Nanocyl-7000 exposure. In fact, animal reports have demonstrated that Nanocyl-7000 can also lead to fibrosis development, which, however, is not as severe as the one observed with longer types of MWCNTs. ${ }^{35}$ In vivo results correlate with our in vitro findings, since Nanocyl-7000 evoked a fibrogenic response, but to a lesser extent compared to Mitsui-7. However, it should be noted that existing in vivo studies only reflect an acute scenario, and the fact that some of the classic fibrotic markers are absent or expressed to a lesser extent following exposure to Nanocyl does not preclude the possibility that this CNT type might still induce fibrosis through a different mechanism at different doses or postexposure time points.

In parallel, the pulmonary fibrotic activity of lung cultures exposed to crystalline silica, i.e., Min-U-Sil, was assessed, as this material has shown fibrotic effects in vivo. ${ }^{29,30}$ Similar to in vivo studies, our results demonstrated that Min-U-Sil induced significant profibrotic effects in epithelial cells and macrophage cultures following 96 hours of exposure, and in fibroblasts following 24 hours of exposure. Notably, significant collagen formation in fibroblasts was observed only after prolonged exposure to Min-U-Sil, indicating that fibroblast activation may require a longer time frame to occur, compared to the first effects of fibrosis that is, fibrotic marker release (TGF- $\beta$ and PD-GF).

In addition, it was shown that a proinflammatory response following exposure to Mitsui-7 MWCNTs can occur rapidly following 24 hours of exposure, while signs of profibrotic activity required a prolonged ( 96 hours) exposure, which points out the importance of evaluating hazard assessment upon long-term exposure periods. This finding correlates with a recent in vivo report, where fibrotic effects of Mitsui-7 were apparent at time points later than 28 days. $^{77}$

\section{Conclusion}

The purpose of this study was to gain an insight into the early profibrotic activity of three key lung cell monocultures involved either directly or indirectly in the development of pulmonary fibrosis. Unlike most in vitro toxicity studies, the biological impact was evaluated not only upon acute exposures (24 hours) but also after a prolonged incubation time (96 hours). Following each exposure period, a panel of crucial mediators was assessed, carefully selected for their predictive fibrotic capability. However, it should be pointed out that existing in vitro assays are not able to predict the disease in its entirety, so more research is required in future studies in that perspective. The results have shown that exposure to MWCNTs affected each cell type differently. Exposure to long, rigid MWCNTs, but not short MWCNTs, resulted in a proinflammatory response in macrophages and fibroblasts, although predominantly after only 24 hours of exposure. Notably, profibrotic effects were observed in all tested cell types, following prolonged MWCNT incubation (96 hours), thus indicating that long-term exposures can be considered more suitable to predict the early signs of fibrosis in vitro. For future studies, it is recommended to investigate the long-term effects of low nanomaterial concentrations in vitro using more physiologically relevant 3D cellular models. 


\section{Acknowledgments}

The authors would like to thank Dr. Monita Sharma and Dr. Amy J. Clippinger (PETA International Science Consortium Ltd.) for their support and discussion. This study was supported by the Swiss National Science Foundation (Grant No. 310030_159847/1), PETA International Science Consortium Ltd., and the Adolphe Merkle Foundation.

\section{Author Disclosure Statement}

No competing financial interests exist.

\section{References}

1. Nowack B, Connie Brouwer C, Geertsma RE, et al. Analysis of the occupational, consumer and environmental exposure to engineered nanomaterials used in 10 technology sectors. Nanotoxicology 2012:7;1152-1156.

2. Bakand S, Hayes A. Toxicological considerations, toxicity assessment, and risk management of inhaled nanoparticles. Int J Mol Sci 2016:17;929.

3. Hayashi T, Endo M. Carbon nanotubes as structural material and their application in composites. Compos Part B Eng 2011:42;2151-2157.

4. Donaldson K, Aitken R, Tran L, et al. Carbon nanotubes: A review of their properties in relation to pulmonary toxicology and workplace safety. Toxicol Sci 2006:92;5-22.

5. De Volder MF, Tawfick SH, Baughman RH, et al. Carbon Nanotubes: Present and future commercial cpplications. Science 2013:339;535-539.

6. Maynard AD, Baron PA, Foley M, et al. Exposure to carbon nanotube material: Aerosol release during the handling of unrefined single-walled carbon nanotube material. J Toxicol Environ Health 2004:67;87-107.

7. Donaldson K, Murphy FA, Duffin R, et al. Asbestos, carbon nanotubes and the pleural mesothelium: A review of the hypothesis regarding the role of long fibre retention in the parietal pleura, inflammation and mesothelioma. Part Fibre Toxicol 2010:7;5.

8. Poland CA, Duffin R, Kinloch I, et al. Carbon nanotubes introduced into the abdominal cavity of mice show asbestoslike pathogenicity in a pilot study. Nat Nanotech 2008:3; 423-428.

9. Kasai T, Umeda Y, Ohnishi M, et al. Lung carcinogenicity of inhaled multi-walled carbon nanotube in rats. Part Fibre Toxicol 2016:13;53.

10. Donaldson K, Murphy F, et al. Identifying the pulmonary hazard of high aspect ratio nanoparticles to enable their safety-by-design. Nanomedicine (Lond) 2011:6;143-156.

11. Lam CW, James JT, McCluskey R, et al. Pulmonary toxicity of singlewall carbon nanotubes in mice 7 and 90 days after intratracheal instillation. Toxicol Sci 2004:77;126-134.

12. Mercer RR, Scabilloni JF, Hubbs AF, et al. Extrapulmonary transport of MWCNT following inhalation exposure. Part Fibre Toxicol 2013:10;38.

13. Mercer RR, Scabilloni JF, Hubbs AF, et al. Distribution and fibrotic response following inhalation exposure to multiwalled carbon nanotubes. Part Fibre Toxicol 2013:10;33.

14. Snyder-Talkington BN, Dong C, Porter DW, et al. Multiwalled carbon nanotube-induced pulmonary inflammatory and fibrotic responses and genomic changes following aspiration exposure in mice: A 1-year postexposure study. J Toxicol Environ Health A 2016:79;352-366.
15. Vietti G, Lison D, van den Brule S. Mechanisms of lung fibrosis induced by carbon nanotubes: Towards an Adverse Outcome Pathway (AOP). Part Fibre Toxicol 2016:13;11.

16. Shvedova AA, Kisin E, Murray AR, et al. Inhalation vs. aspiration of single-walled carbon nanotubes in C57BL/6 mice: Inflammation, fibrosis, oxidative stress, and mutagenesis. Am J Physiol Lung Cell Mol Physiol 2008:295;552565.

17. Pauluhn J. Subchronic 13-week inhalation exposure of rats to multiwalled carbon nanotubes: Toxic effects are determined by density of agglomerate structures, not fibrillar structures. Toxicol Sci 2010:113;226-242.

18. Mercer RR, Hubbs AF, Scabilloni JF, et al. Pulmonary fibrotic response to aspiration of multi-walled carbon nanotubes. Part Fibre Toxicol 2011:8;21.

19. Ma-Hock L, Treumann S, Strauss V, et al. Inhalation toxicity of multiwall carbon nanotubes in rats exposed for 3 months. Toxicol Sci 2009:112;468-481.

20. Mitchell LA, Gao J, Wal RV, et al. Pulmonary and systemic immune response to inhaled multiwalled carbon nanotubes. Toxicol Sci 2007:100;201-214.

21. Roda E, Coccini T, Acerbi D, et al. Comparative pulmonary toxicity assessment of pristine and functionalized multiwalled carbon nanotubes intratracheally instilled in rats: Morphohistochemical evaluations. Histol Histopathol 2011:26;357-367.

22. Sharma M, Nikota J, Halappanavar S, et al. Predicting pulmonary fibrosis in humans after exposure to multi-walled carbon nanotubes (MWCNTs). Arch Toxicol 2016:90; 1605-1622.

23. Chen T, Nie H, Gao X, et al. Epithelial-mesenchymal transition involved in pulmonary fibrosis induced by multiwalled carbon nanotubes via TGF-beta/Smad signaling pathway. Toxicol Let 2014:226;150-162.

24. Ryman-Rasmussen JP, Tewksbury EW, Moss OR, et al. Inhaled multiwalled carbon nanotubes potentiate airway fibrosis in murine allergic asthma. Am J Respir Cell Mol Biol 2009:40;349-358.

25. Labib S, Williams A, Yauk CL, et al. Nano-risk Science: Application of toxicogenomics in an adverse outcome pathway framework for risk assessment of multi-walled carbon nanotubes. Part Fibre Toxicol 2016:13;15.

26. Wynn TA. Integrating mechanisms of pulmonary fibrosis. J Exp Med 2011:208;1339-1350.

27. Wang P, Nie X, Wang Y, et al. Multiwall carbon nanotubes mediate macrophage activation and promote pulmonary fibrosis through TGF-beta/Smad signaling pathway. Small 2013:9;3799-3811.

28. Hussain S, Sangtian S, Anderson SM, et al. Inflammasome activation in airway epithelial cells after multi-walled carbon nanotube exposure mediates a profibrotic response in lung fibroblasts. Part Fibre Toxicol 2014:11;28.

29. Warheit DB, Webb TR, Colvin VL, et al. Pulmonary bioassay studies with nanoscale and fine-quartz particles in rats: Toxicity is not dependent upon particle size but on surface characteristics. Toxicol Sci 2007:95;270-280.

30. Vietti G, Ibouraadaten S, Palmai-Pallag M, et al. Towards predicting the lung fibrogenic activity of nanomaterials: Experimental validation of an in vitro fibroblast proliferation assay. Part Fibre Toxicol 2013:10.

31. Schneider CA, Rasband WS, Eliceiri KW. NIH Image to ImageJ: 25 years of image analysis. Nat Methods 2012:9; 671-675. 
32. Smith BR, Ghosn EE, Rallapalli H, et al. Selective uptake of single-walled carbon nanotubes by circulating monocytes for enhanced tumour delivery. Nat Nanotechnol 2014:9; 481-487.

33. Clift MJ, Gehr P, Rothen-Rutishauser B. In vitro testing for nanotoxicology: A valid alternative? Arch Toxicol 2011b: 85;713-731.

34. Saber AT, Mortensen A, Szarek J, et al. Epoxy composite dusts with and without carbon nanotubes cause similar pulmonary responses, but differences in liver histology in mice following pulmonary deposition. Part Fibre Toxicol 2016: $13 ; 37$.

35. Poulsen SS, Saber AT, Williams A, et al. MWCNTs of different physicochemical properties cause similar inflammatory responses, but differences in transcriptional and histological markers of fibrosis in mouse lungs. Toxicol Appl Pharmacol 2015:84;16-32.

36. Sharma L, Wu W, Dholakiya SL, et al. Assessment of phagocytic activity of cultured macrophages using fluorescence microscopy and flow cytometry. Methods Mol Biol 2014:1172;137-145.

37. Wörle-Knirsch JM, Pulskamp K, Krug HF. Oops they did it again! Carbon nanotubes hoax scientists in viability assays. Nano let 2006:6;1261-1268.

38. Chortarea S, Clift MJD, Vanhecke D, et al. Repeated exposure to carbon nanotube-based aerosols does not affect the functional properties of a 3D human epithelial airway model. Nanotoxicology 2015:9;983-993.

39. Wang X, Xia T, Duch MC, et al. Pluronic F108 coating decreases the lung fibrosis potential of multiwall carbon nanotubes by reducing lysosomal injury. Nano let 2012:12; 3050-3061.

40. Bonner J. Mesenchymal cell survival in airway and interstitial pulmonary fibrosis. Fibrog Tissue Repair 2010:3;15.

41. Wang X, Duch MC, Mansukhani N, et al. Use of a profibrogenic mechanism-based predictive toxicological approach for tiered testing and decision analysis of carbonaceous nanomaterials. ACS Nano 2015:9;3032-3043.

42. Eatemadi A, Daraee H, Karimkhanloo H, et al. Carbon nanotubes: Properties, synthesis, purification, and medical applications. Nanoscale Res Lett 2014:9;393.

43. Donaldson K, Poland CA, Murphy FA, et al. Pulmonary toxicity of carbon nanotubes and asbestos-similarities and differences. Adv Drug Deliv Rev 2013:65;2078-2086.

44. Sargent LM, Porter DW, Staska LM, et al. Promotion of lung adenocarcinoma following inhalation exposure to multi-walled carbon nanotubes. Part Fibre Toxicol 2014: $11 ; 3$.

45. Borm P, Cassee F, Oberdörster G. Lung particle overload: Old school-new insights? Part Fibre Toxicol 2015:12;10.

46. Gangwal S, Brown JS, Wang A, et al. Informing selection of nanomaterial concentrations for ToxCast in vitro testing based on occupational exposure potential. Environ Health Perspect 2011:119;1539-1546.

47. Grosse Y, Loomis D, Guyton KZ, et al. Carcinogenicity of fluoro-edenite, silicon carbide fibres and whiskers, and carbon nanotubes. Lancet Oncol 2014:15:1427-1428.

48. Xu J, Futakuchi M, Shimizu H, et al. Multi-walled carbon nanotubes translocate into the pleural cavity and induce visceral mesothelial proliferation in rats. Cancer Sci 2012:103; 2045-2050.

49. Nagai H, Okazaki Y, Chew SH, et al. Diameter and rigidity of multiwalled carbon nanotubes are critical factors in me- sothelial injury and carcinogenesis. Proc Natl Acad Sci U S A 2011:108;1330-1338.

50. Treumann S, Ma-Hock L, Gröters S, et al. Additional histopathologic examination of the lungs from a 3-month inhalation toxicity study with multiwall carbon nanotubes in rats. Toxicol Sci 2013:134;103-110.

51. Thurnherr T, Su DS, Diener L, et al. Comprehensive evaluation of in vitro toxicity of three large-scale produced carbon nanotubes on human jurkat $\mathrm{T}$ cells and a comparison to crocidolite asbestos. Nanotoxicology 2009:3;319-338.

52. Oberdörster G, Castranova V, Asgharian B, et al. Inhalation exposure to carbon nanotubes (CNT) and carbon nanofibers (CNF): Methodology and dosimetry. J Toxicol Environ Health B Crit Rev 2015:18;121-212.

53. Polimeni M, Gulino GR, Gazzano E, et al. Multi-walled carbon nanotubes directly induce epithelial-mesenchymal transition in human bronchial epithelial cells via the TGF$\beta$-mediated Akt/GSK-3 $\beta /$ SNAIL-1 signalling pathway. Part Fibre Toxicol 2016:13;27.

54. van Berlo D, Wilhelmi V, Boots AW, et al. Apoptotic, inflammatory, and fibrogenic effects of two different types of multi-walled carbon nanotubes in mouse lung. Arch Toxicol 2014:88;1725-1737.

55. Takaya M, Serita F, Yamazaki K, et al. Characteristics of multiwall carbon nanotubes for an intratracheal instillation study with rats. Ind Health 2010:48;452-459.

56. Schinwald A, Murphy FA, Prina-Mello A, et al. The threshold length for fiber-induced acute pleural inflammation: Shedding light on the early events in asbestos-induced mesothelioma. Toxicol Sci 2012:128;461-470.

57. Sweeney S, Berhanu D, Misra SK, et al. Multi-walled carbon nanotube length as a critical determinant of bioreactivity with primary human pulmonary alveolar cells. Carbon 2014:78;26-37.

58. Boyles MS, Young L, Brown DM, et al. Multi-walled carbon nanotube induced frustrated phagocytosis, cytotoxicity and pro-inflammatory conditions in macrophages are length dependent and greater than that of asbestos. Toxicol In Vitro 2015:29;1513-1528.

59. Alarifi S, Ali D. Mechanisms of multi-walled carbon nanotubes-induced oxidative stress and genotoxicity in mouse fibroblast cells. Int J Toxicol 2015:34;258-265.

60. Shvedova AA, Kisin ER, Mercer R, et al. Unusual inflammatory and fibrogenic pulmonary responses to single-walled carbon nanotubes in mice. Am J Physiol Lung Cell Mol Physiol 2005:289;698-708.

61. Li Z, Hulderman T, Salmen R, et al. Cardiovascular effects of pulmonary exposure to single-wall carbon nanotubes. Environ Health Perspect 2007:115;377-382.

62. Azad N, Iyer AK, Wang L, et al. Reactive oxygen speciesmediated p38 MAPK regulates carbon nanotube-induced fibrogenic and angiogenic responses. Nanotoxicology 2013: $7 ; 157-168$.

63. Siani A, Tirelli N. Myofibroblast differentiation: Main features, biomedical relevance, and the role of reactive oxygen species. Antioxid Redox Signal 2014:21;768-785.

64. Dong J, Ma Q. Myofibroblasts and lung fibrosis induced by carbon nanotube exposure. Part Fibre Toxicol 2016:13;60.

65. Visalli G, Bertuccio MP, Iannazzo D, et al. Toxicological assessment of multi-walled carbon nanotubes on A549 human lung epithelial cells. Toxicol In Vitro 2015:29:351-362.

66. Ravichandran P, Periyakaruppan A, Sadanandan B, et al. Induction of apoptosis in rat lung epithelial cells by 
multiwalled carbon nanotubes. J Biochem Mol Toxicol 2009:23;333-344.

67. Rothen-Rutishauser B, Brown DM, Piallier-Boyles M, et al. Relating the physicochemical characteristics and dispersion of multiwalled carbon nanotubes in different suspension media to their oxidative reactivity in vitro and inflammation in vivo. Nanotoxicology 2010:4;331-342.

68. Wang X, Xia T, Ntim SA, et al. Dispersal state of multiwalled carbon nanotubes elicits profibrogenic cellular responses that correlate with fibrogenesis biomarkers and fibrosis in the murine lung. ACS Nano 2011:5;9772-9787.

69. He X, Young SH, Schwegler-Berry D, et al. Multiwalled carbon nanotubes induce a fibrogenic response by stimulating reactive oxygen species production, activating NF- $\kappa \mathrm{B}$ signaling, and promoting fibroblast-to-myofibroblast transformation. Chem Res Toxicol 2011:24;2237-2248.

70. Fu C, Liu T, Li L, et al. Effects of graphene oxide on the development of offspring mice in lactation period. Biomaterials 2015:40;23-31.

71. Hamilton RF Jr, Xiang C, Li M, et al. Purification and sidewall functionalization of multiwalled carbon nanotubes and resulting bioactivity in two macrophage models. Inhal Toxicol 2013:25;199-210.

72. Palomäki J, Välimäki E, Sund J, et al. Long, needle-like carbon nanotubes and asbestos activate the NLRP3 inflammasome through a similar mechanism. ACS Nano 2011:5; 6861-6870.

73. Murphy FA, Schinwald A, Poland CA, et al. The mechanism of pleural inflammation by long carbon nanotubes:
Interaction of long fibres with macrophages stimulates them to amplify pro-inflammatory responses in mesothelial cells. Part Fibre Toxicol 2012:9;8.

74. Bonner JC. Regulation of PDGF and its receptors in fibrotic diseases. Cytokine Growth Factor Rev 2004:15;255-273.

75. Li R, Wang X, Ji Z, et al. Surface charge and cellular processing of covalently functionalized multiwall carbon nanotubes determine pulmonary toxicity. ACS Nano 2013:7; 2352-2368.

76. Wang X, Xia T, Ntim SA, et al. Quantitative techniques for assessing and controlling the dispersion and biological effects of multiwalled carbon nanotubes in mammalian tissue culture cells. ACS Nano 2010:4;7241-7252.

77. Snyder-Talkington BN, Pacurari M, Dong C, et al. Systematic analysis of multiwalled carbon nanotube-induced cellular signaling and gene expression in human small airway epithelial cells. Toxicol Sci 2013:133;79-89.

Address correspondence to: Prof. Dr. Barbara Rothen-Rutishauser BioNanomaterials Adolphe Merkle Institute Université de Fribourg Chemin des Verdiers 4 $\mathrm{CH}-1700$ Fribourg Switzerland

E-mail: barbara.rothen@unifr.ch 